Article

\title{
Viscoelastic Behavior of Polymer-Modified Cement Pastes: Insight from Downscaling Short-Term Macroscopic Creep Tests by Means of Multiscale Modeling
}

\author{
Luise Göbel 1,2,*,+, Markus Königsberger ${ }^{2,3}$ (D), Andrea Osburg 1 (i) and Bernhard Pichler ${ }^{2}$ \\ 1 F.A. Finger-Institute for Building Material Engineering, Bauhaus-Universität Weimar, 99423 Weimar, \\ Germany; andrea.osburg@uni-weimar.de \\ 2 Institute for Mechanics of Materials and Structures, TU Wien-Vienna University of Technology, \\ 1040 Vienna, Austria; mkonigsb@ulb.ac.be (M.K.); bernhard.pichler@tuwien.ac.at (B.P.) \\ 3 BATir Department, Université libre de Bruxelles (ULB), 1050 Bruxelles, Belgium \\ * Correspondence: luise.goebel@uni-weimar.de; Tel.: +49-3643-584743 \\ + Current address: Coudraystraße 11 A, 99423 Weimar, Germany.
}

Received: 28 February 2018; Accepted: 21 March 2018; Published: 23 March 2018

\begin{abstract}
Adding polymers to cementitious materials improves their workability and impermeability, but also increases their creep activity. In the present paper, the creep behavior of polymer-modified cement pastes is analyzed based on macroscopic creep tests and a multiscale model. The continuum micromechanics model allows for "downscaling" the results of macroscopic hourly-repeated ultra-short creep experiments to the viscoelastic behavior of micron-sized hydration products and polymer particles. This way, the increased creep activity of polymer-modified cement pastes is traced back to an isochoric power-law-type creep behavior of the polymers. The shear creep modulus of the polymers is found (i) to be two orders of magnitude smaller than that of the hydrates and (ii) to increase considerably with increasing material age. The latter result suggests that the creep activity of the polymers decreases with the self-desiccation-related decrease of the relative humidity inside the air-filled pores of cement paste. Furthermore, its decrease is most likely related to the penetration of cementitious hydrates into compliant polymer agglomerates.
\end{abstract}

Keywords: polymer modification; cement paste; creep; micromechanics; viscoelasticity

\section{Introduction}

Polymer-modified mortars and concretes (PCC) have gained wide attention in the fields of repair, restoration and construction [1-3]. The polymers are added, either in the form of redispersible powders or aqueous dispersions, in order to improve workability, impermeability, adhesive strength or ductility [4-6]. However, adding polymers to cementitious materials reduces their elastic stiffness and increases their creep activity compared to unmodified pastes [5-9]. The pronounced creep activity of sprayable polymer cement concretes (SPCC) $[10,11]$ is beneficial for tunnel linings produced by means of the New Austrian Tunneling Method [12,13], because creep decreases compressive stresses in the lining, which result from the inward moving ground mass. For many other applications, the increased creep activity is not necessarily an advantage. Therefore, quantitative knowledge regarding the early-age creep behavior of polymer-modified cementitious materials is of significant importance.

Macroscopic early-age experiments provide valuable insight into the creep behavior of cementitious materials. As for conventional (unmodified) materials, creep testing enjoys a tradition of already more than 100 years $[14,15]$ and typically consists of long-term creep tests with durations 
of several days to several years; see, e.g., the comprehensive creep database of Bažant and Li [16]. Rather recently, short-term early-age creep testing protocols were developed [17-22]. They include regularly-repeated creep tests with durations of a few minutes only, during which the chemical reaction between the binder and the water does not progress significantly. Therefore, regularly-repeated ultra-short creep tests provide insight into the hydration-driven evolution of the elastic stiffness and the non-aging creep properties of cementitious materials. The creep testing protocol of Irfan-ul Hassan et al. [19] was already applied to polymer-modified cement pastes [9]. This showed that polymer-modified cement pastes exhibit a smaller elastic stiffness, as well as a larger creep compliance compared to unmodified reference pastes. In the present contribution, the described short-term creep tests are further evaluated. Thereby, the focus rests on exploiting the macroscopic creep testing data, in the context of top-down analysis, such as to get quantitative insight into the creep properties of the microscopic polymer particles. Multiscale modeling is used as the vehicle for the required macro-to-micro-scale-transition.

Multiscale models, developed in the framework of continuum micromechanics, have been successfully applied to cementitious materials, in order to predict the hydration-induced evolutions of their elastic stiffness [9,23-28], their compressive strength [29-31] and their viscoelastic behavior $[22,32,33]$. The hierarchically-organized microstructure of cement pastes was resolved down to the scales of the observation of unhydrated cement grains, capillary pores and hydration products (called "hydrates"). Universal, i.e., age- and composition-independent (visco-)elastic and strength constants of these microstructural constituents have been (i) identified and (ii) shown to be the origin of the age- and composition-dependent macroscopic material behavior of cementitious materials. The significance of the universal creep properties of the hydrates, identified by Königsberger et al. [33], was corroborated by comparing model-predicted creep functions with results from the independent creep tests of Tamtsia and Beaudoin [34], who performed 30-day-long creep tests on 30-year-old Portland cement pastes.

The present paper aims at understanding and quantifying the micromechanical origin of the more pronounced creep activity of polymer-modified cement pastes. To this end, we (i) employ the aforementioned universal creep properties of hydrates from [33] and (ii) check whether or not the universality of creep properties also applies to the polymers distributed within the microstructure of cement paste. Thereby, the microstructure of cement paste is represented by means of a two-scale model. The latter follows (i) Pichler et al. [26] by introducing needle-shaped (rather than spherical) hydrates, (ii) Pichler and Hellmich [29] by distinguishing the "hydrate foam"-scale from the "cement paste"-scale, as well as (iii) Göbel et al. [28] by introducing a spherical polymer phase at the same scale as the hydrate needles and the capillary pores. The multiscale model is used to "downscale" results from the aforementioned macroscopic ultra-short creep tests on polymer-modified cement pastes [9] to the creep properties of micrometer-sized polymers.

The remainder of the paper is organized as follows. The multiscale model for elasticity and creep homogenization of polymer-modified cement pastes is discussed in Section 2. The developed scale-transition relations establish a link between the microscopic creep behavior of the polymer particles and the macroscopic creep behavior of the polymer-modified cement pastes. This opens the door to the top-down identification of the polymer creep behavior, described in Section 2. The available short-term creep tests on polymer-modified cement pastes are briefly summarized in Section 3.1. Two different strategies for top-down identification of the creep behavior of the polymer particles are implemented: (i) consideration of age-independent and, thus, constant creep properties of the polymers (see Section 3.2) and (ii) age-dependent and, thus, evolving creep properties (see Section 3.3). The paper finishes with concluding remarks (see Section 4 ). 


\section{Modeling the Hydration-Induced Evolutions of the Non-Aging Creep Properties of Polymer-Modified Cement Pastes}

\subsection{Micromechanical Representation of Polymer-Modified Cement Pastes}

Cement pastes exhibit a hierarchically-organized microstructure that can be represented by means of two scale-separated representative volume elements (RVEs) [29]: a polycrystalline RVE of hydrate foam, at the micron scale, and a matrix-inclusion-type RVE of cement paste, at the sub-millimeter scale (see Figure 1). Thereby, the heterogeneous microstructure of cement paste is considered to consist of quasi-homogeneous sub-domains, called material phases. They are spherical unhydrated cement grains, spherical pores and needle-shaped hydration products [26]. As for the present paper, which refers to polymer-modified cement pastes, we follow Göbel et al. [28] by introducing spherical polymer particles at the same scale as the hydration products and the capillary pores (see Figure 1).

The RVE of cement paste is modeled as a matrix-inclusion composite consisting of a hydrate foam matrix and two inclusion phases: unhydrated cement particles and entrapped air pores. The latter stem from interaction processes between the additives of the polymer and the other raw materials $[35,36]$. The heterogeneous nature of the hydrate foam matrix is resolved at the next smaller scale of observation. The RVE of the hydrate foam is modeled as a polycrystalline composite consisting of spherical polymer particles, spherical water- or air-filled capillary pores and isotropically-oriented needle-shaped hydrates. These material phases are in direct mutual interaction [28]. The spherical shape of submicron-sized polymer particles [37] is motivated by scanning electron microscopy images of polymer dispersions and powders [38].

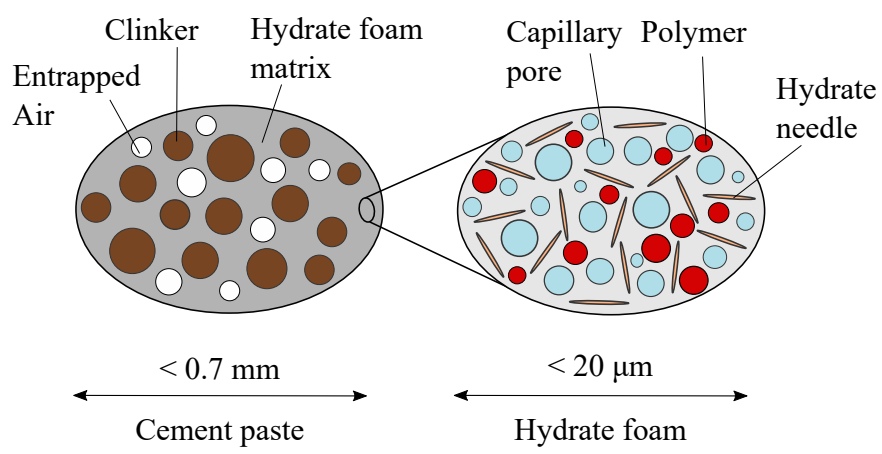

Figure 1. Micromechanical representation of polymer-modified cement pastes after [9]; the two-dimensional sketches refer to three-dimensional representative volume elements (RVEs).

\subsection{Viscoelastic Phase Properties}

For conventional cementitious materials, the macroscopic creep behavior has been attributed to the hydration products only $[32,39,40]$, while all other material phases are considered to exhibit purely elastic behavior. As for polymer-modified cement pastes, in turn, we consider that not only the hydrates, but also the polymers exhibit viscoelastic behavior, defined as [41],

$$
\begin{aligned}
& \sigma_{j}(t)=\int_{-\infty}^{t} \mathbb{R}_{j}(t-\tau): \frac{\partial \varepsilon_{j}(\tau)}{\partial \tau} d \tau, \\
& \varepsilon_{j}(t)=\int_{-\infty}^{t} \mathbb{J}_{j}(t-\tau): \frac{\partial \sigma_{j}(\tau)}{\partial \tau} d \tau,
\end{aligned}
$$


where $\sigma_{j}$ and $\varepsilon_{j}$ are phase stresses and strains, $\mathbb{R}_{j}$ and $\mathbb{J}_{j}$ denote the phase relaxation and creep tensor functions, $\tau$ is the time instant of loading and $t$ is the chronological time. Notably, creep and relaxation tensor functions of any phase $j$ are linked by means of the following convolution condition [42]:

$$
\int_{-\infty}^{t} \mathbb{J}_{j}(t-\tau): \mathbb{R}_{j}(\tau) \mathrm{d} \tau=\int_{-\infty}^{t} \mathbb{R}_{j}(t-\tau): \mathbb{J}_{j}(\tau) \mathrm{d} \tau=t \mathbb{I},
$$

where II denotes the symmetric fourth-order identity tensor with the components $I_{i j k l}=\frac{1}{2}\left(\delta_{i k} \delta_{j l}+\delta_{i l} \delta_{j k}\right)$ and where $\delta_{i j}$ is the Kronecker delta, with components $\delta_{i j}=1$ for $i=j$, and zero, otherwise. The capillary pores, the unhydrated cement and the entrapped air phases behave elastically, expressed as:

$$
\sigma_{j}(t)=\mathbb{C}_{j}: \varepsilon_{j}(t), \quad j \in\{\text { por, cem, air }\},
$$

where $\mathbb{C}_{j}$ denotes the phase stiffness tensor. Equation (3) entails that their relaxation functions are time-invariant according to:

$$
\mathbb{R}_{j}=\mathbb{C}_{j}=3 k_{j} \mathbb{I}^{\mathrm{vol}}+2 \mu_{j} \mathbb{I}^{\mathrm{dev}}, \quad j \in\{\text { por, cem, air }\} .
$$

$k_{j}$ and $\mu_{j}$ denote the bulk and the shear moduli of phase $j$ (see Table 1 ), and $\mathbb{I}^{\mathrm{vol}}$ and $\mathbb{I}^{\mathrm{dev}}$ are the volumetric and deviatoric parts of the identity tensor $\mathbb{I}$.

Table 1. Elastic properties and mass densities of the material phases in polymer-modified cement pastes.

\begin{tabular}{ccccc}
\hline Phase & $\begin{array}{c}\text { Bulk Modulus } \\
(\mathbf{G P a})\end{array}$ & $\begin{array}{c}\text { Shear Modulus } \\
\mathbf{( G P a})\end{array}$ & $\begin{array}{c}\text { Mass Densities } \\
\left(\mathbf{g ~ c m} \mathbf{~ c m}^{-3}\right)\end{array}$ & Reference \\
\hline Air & $k_{\text {air }}=0$ & $\mu_{\text {air }}=0$ & $\rho_{\text {air }}=0$ & \\
Water & $k_{\text {water }}=0$ & $\mu_{\text {water }}=0$ & $\rho_{\text {water }}=1.00$ & \\
Hydrates & $k_{\text {hyd }}=18.69$ & $\mu_{\text {hyd }}=11.76$ & $\rho_{\text {hyd }}=2.073$ & {$[23,29,43]$} \\
Cement & $k_{\text {cem }}=116.70$ & $\mu_{\text {cem }}=53.80$ & $\rho_{\text {cem }}=3.15$ & {$[33,44]$} \\
Polymer P1 & $k_{\mathrm{P} 1}=3.97$ & $\mu_{\mathrm{P} 1}=0.85$ & $\rho_{\mathrm{P} 1}=1.03$ & {$[8,9]$} \\
Polymer P2 & $k_{\mathrm{P} 2}=4.02$ & $\mu_{\mathrm{P} 2}=0.86$ & $\rho_{\mathrm{P} 2}=1.02$ & {$[8,9]$} \\
\hline
\end{tabular}

The creep tensor functions of hydrates and polymers are introduced as follows. Königsberger et al. [33] performed a top-down analysis of more than 500 ultra-short early-age creep tests on conventional cement pastes, with different compositions in terms of different water-to-cement ratios. Very remarkably, the large macroscopic database could be explained based on one universal isochoric creep tensor function of the microscopic hydrates, reading as:

$$
\mathbb{J}_{\text {hyd }}(t-\tau)=\frac{1}{3 k_{\text {hyd }}} \mathbb{I}^{\mathrm{vol}}+\frac{1}{2}\left[\frac{1}{\mu_{\text {hyd }}}+\frac{1}{\mu_{c, \text { hyd }}}\left(\frac{t-\tau}{t_{\text {ref }}}\right)^{\beta_{\text {hyd }}}\right] \mathbb{I}^{\text {dev }} .
$$

In Equation (5), $t_{\text {ref }}=1 \mathrm{~d}=86,400 \mathrm{~s}$ is the reference time; $k_{\text {hyd }}$ and $\mu_{\text {hyd }}$ denote the universal bulk and shear modulus of the hydrates (see Table 1); and $\mu_{c, \text { hyd }}$ and $\beta_{\text {hyd }}$ are the universal shear creep modulus and the power-law creep exponent of the hydrates, amounting to [33]:

$$
\mu_{c, \text { hyd }}=20.93 \mathrm{GPa}, \quad \beta_{\text {hyd }}=0.251 \text {. }
$$

As for the polymers, we consider that their creep behavior is also isochoric. Furthermore, it is recalled that the creep behavior measured in macroscopic creep tests on different polymers could be modeled 
using a power-law [45-47]. This is the motivation to introduce the creep tensor function of the polymers, $\mathbb{J}_{\text {pol }}(t-\tau)$, as:

$$
\mathbb{J}_{\mathrm{pol}}(t-\tau)=\frac{1}{3 k_{\mathrm{pol}}} \mathbb{I}^{\mathrm{vol}}+\frac{1}{2}\left[\frac{1}{\mu_{\mathrm{pol}}}+\frac{1}{\mu_{c, \mathrm{pol}}}\left(\frac{t-\tau}{t_{\mathrm{ref}}}\right)^{\beta_{\mathrm{pol}}}\right] \mathbb{I}^{\mathrm{dev}},
$$

where $k_{\mathrm{pol}}$ and $\mu_{\mathrm{pol}}$ denote the elastic bulk and shear moduli of the polymers and $\mu_{c, \text { pol }}$ and $\beta_{\mathrm{pol}}$ denote their shear creep modulus and the power-law exponent, respectively. While the elastic stiffness properties of the polymers can be readily identified, e.g., by ultrasonic testing [9], direct experimental characterization of the polymer creep parameters $\mu_{c \text {,pol }}$ and $\beta_{\text {pol }}$ is out of reach. As a remedy, they are identified from macroscopic creep tests by means of "downscaling". In this context, scale-transition relations linking the microscopic viscoelastic phase behavior to the macroscopic creep behavior are required.

\subsection{Homogenization of the Viscoelastic Properties of Polymer-Modified Cement Paste}

Homogenization of the viscoelastic phase behavior is performed in the theoretical framework of non-aging microviscoelasticity based on the correspondence principle [48]. In the first step, the viscoelastic phase behavior is transformed from the time domain to the Laplace-Carson (LC) domain. The LC transform $f^{*}(p)$ of a time-dependent function $f(t)$ is given as:

$$
f^{*}(p)=p \int_{0}^{\infty} f(t) e^{-p t} d t
$$

where $p$ is the complex variable in the LC domain and the symbol $(\bullet)^{*}$ stands for the LC transform of the time-dependent quantity $(\bullet)$. Applying the LC transformation rule (8) to the viscoelastic phase behavior according to Equations (1) and (3) results in a simple algebraic relation between LC transformed phase stresses $\sigma_{j}^{*}$ and strains $\varepsilon_{j}^{*}$, reading as:

$$
\sigma_{j}^{*}(p)=\mathbb{R}_{j}^{*}(p): \varepsilon_{j}^{*}(p), \quad \varepsilon_{j}^{*}(p)=\mathbb{J}_{j}^{*}(p): \sigma_{j}^{*}(p) .
$$

where interestingly:

$$
\mathbb{J}_{j}^{*}(p)=\left[\mathbb{R}_{j}^{*}(p)\right]^{-1} .
$$

Given that Equation (9) is formally identical to a linear elastic law, homogenization schemes for elasticity can be applied, in the second step, to the homogenization of viscoelastic properties in the LC space. In the third step, the solution, i.e., the homogenized viscoelastic behavior, is back-transformed from the LC space to the time domain.

Transformation of the viscoelastic phase properties of the hydrates, given in Equation (5), and of the polymers, given in Equation (7), according to the transformation rule (8), and consideration of the relation (10) yield LC relaxation tensor functions reading as [33]:

$$
\begin{aligned}
\mathbb{R}_{j}^{*}(p) & =3 k_{j} \mathbb{I}^{\mathrm{Vol}}+2 \mu_{j}^{*}(p) \mathbb{I}^{\mathrm{dev}} \\
& =3 k_{j} \mathbb{I}^{\mathrm{Vol}}+2\left[\frac{1}{\mu_{j}}+\frac{1}{\mu_{c, j}}\left(\frac{1}{t_{\text {ref }}}\right)^{\beta_{j}} \Gamma\left(\beta_{j}+1\right) p^{-\beta_{j}}\right]^{-1} \mathbb{I}^{\mathrm{dev}}, \quad j \in\{\text { hyd, pol }\},
\end{aligned}
$$

with $\Gamma$ denoting the gamma function. As for the purely elastic phases, according to Equation (4), the LC transformed relaxation tensor functions are equal to the stiffness tensor:

$$
\mathbb{R}_{j}^{*}=\mathbb{C}_{j}=3 k_{j} \mathbb{I}^{\mathrm{vol}}+2 \mu_{j} \mathbb{I}^{\mathrm{dev}} \quad j \in\{\text { por, cem, air }\}
$$


Viscoelasticity homogenization in LC space is carried out using standard homogenization schemes of continuum micromechanics [49]. The polycrystalline "hydrate foam" (Figure 1) is homogenized by means of the related self-consistent scheme [50]. The corresponding relaxation tensor in the LC domain, $\mathbb{R}_{h f}^{*}$, reads as:

$$
\begin{aligned}
\mathbb{R}_{h f}^{*}(p)= & \left\{\sum_{j} f_{j}^{h f} \mathbb{R}_{j}^{*}(p):\left[\mathbb{I}+\mathbb{P}_{\mathrm{sph}}^{h f, *}(p):\left(\mathbb{R}_{j}^{*}(p)-\mathbb{R}_{h f}^{*}(p)\right)\right]^{-1}+f_{\mathrm{hyd}}^{h f} \mathbb{R}_{\mathrm{hyd}}^{*}(p)\right. \\
& \left.: \int_{0}^{2 \pi} \int_{0}^{\pi}\left[\mathbb{I}+\mathbb{P}_{\mathrm{cyl}}^{h f, *}(p, \varphi, \vartheta):\left(\mathbb{R}_{\mathrm{hyd}}^{*}(p)-\mathbb{R}_{h f}^{*}(p)\right)\right]^{-1} \frac{\sin \vartheta \mathrm{d} \vartheta \mathrm{d} \varphi}{4 \pi}\right\} \\
& :\left\{\sum_{j} f_{j}^{h f}:\left[\mathbb{I}+\mathbb{P}_{\mathrm{sph}}^{h f, *}(p):\left(\mathbb{R}_{j}^{*}(p)-\mathbb{R}_{h f}^{*}(p)\right)\right]^{-1}+f_{\mathrm{hyd}}^{h f}\right. \\
& \left.: \int_{0}^{2 \pi} \int_{0}^{\pi}\left[\mathbb{I}+\mathbb{P}_{\mathrm{cyl}}^{h f, *}(p, \varphi, \vartheta):\left(\mathbb{R}_{\mathrm{hyd}}^{*}(p)-\mathbb{R}_{h f}^{*}(p)\right)\right]^{-1} \frac{\sin \vartheta \mathrm{d} \vartheta \mathrm{d} \varphi}{4 \pi}\right\}^{-1}, \\
& j \in\{\text { pol, por }\},
\end{aligned}
$$

where $f_{\text {hyd }}^{h f}, f_{\text {pol }}^{h f}$ and $f_{\text {por }}^{h f}$ denote hydrate foam-related phase volume fractions, whose evolutions are obtained by Powers' hydration model [51]; see Appendix A for mathematical equations expressing the phase volumes as functions of the water-to-cement ratio, the polymer-to-cement ratio and the hydration degree. The orientation of the hydrate needles is accounted for by the Euler angles $\theta$ and $\varphi$. The shape of the phases is considered by means of different Hill tensors, with $\mathbb{P}_{\mathrm{sph}}^{*}$ referring to spherical phases and $\mathbb{P}_{\text {cyl }}^{*}$ to cylindrical phases; see Appendix B and [26,27] for computational details. The matrix-inclusion composite "cement paste" (Figure 1) is homogenized by means of the related Mori-Tanaka scheme $[52,53]$. The homogenized relaxation tensor in the LC domain, $\mathbb{R}_{c p}^{*}$, reads as:

$$
\begin{aligned}
\mathbb{R}_{c p}^{*}(p)= & \left\{f_{\mathrm{hf}}^{c p} \mathbb{R}_{h f}^{*}(p)+\sum_{j} f_{k}^{c p} \mathbb{R}_{k}^{*}(p):\left[\mathbb{I}+\mathbb{P}_{\mathrm{sph}}^{h f, *}(p):\left(\mathbb{R}_{k}^{*}(p)-\mathbb{R}_{h f}^{*}(p)\right)\right]^{-1}\right\} \\
& :\left\{f_{\mathrm{hf}}^{c p} \mathbb{I}+\sum_{j} f_{j}^{c p}:\left[\mathbb{I}+\mathbb{P}_{\mathrm{sph}}^{h f, *}(p):\left(\mathbb{R}_{j}^{*}(p)-\mathbb{R}_{h f}^{*}(p)\right)\right]^{-1}\right\}^{-1}, j \in\{\text { cem, air }\},
\end{aligned}
$$

where $f_{\mathrm{hf}}^{c p}, f_{\mathrm{cem}}^{c p}$ and $f_{\text {air }}^{c p}$ denote cement paste-related phase volume fractions; see Appendix A. The LC transformed creep function of cement paste follows from inversion of $\mathbb{R}_{c p}^{*}$ according to (10).

The "cement paste"-related creep tensor function is finally back-transformed numerically from the LC-domain to the time domain, in order to obtain the modeled creep tensor function as $\mathbb{J}_{c p}^{\bmod }(t-\tau)$. In this context, we follow Scheiner and Hellmich [32] by applying the Gaver-Wynn-Rho algorithm [54,55] and performing the computations in a multi-precision number format. We are interested in the viscous part of the modeled creep function in the time domain, denoted as $\mathbb{J}_{v, c p}^{\bmod }(t-\tau)$, which is defined as:

$$
\mathbb{J}_{v, c p}^{\bmod }(t-\tau)=\mathbb{J}_{c p}^{\bmod }(t-\tau)-\mathbb{J}_{c p}^{\bmod }(t=0),
$$

which will provide the basis for the comparison between modeling results and experiments data and, thus, will allow for the sought quantification of the polymer creep function.

\section{Identification of Polymer Creep Properties Based on Macroscopic Creep Tests}

The characteristic creep properties of the polymers are identified based on (i) the modeled creep function according to Equation (15) and (ii) its experimental counterpart. The latter is obtained from repeated three-minute-long creep tests on polymer-modified cement pastes, as reported in Göbel et al. [9] and summarized next. 


\subsection{Hourly-Repeated Ultra-Short Creep Tests on Polymer-Modified Cement Pastes}

In order to characterize the creep behavior of polymer-modified cement pastes, hourly-repeated three-minute-long creep tests were carried out during the first week after production [9]. The raw materials used for the tests were a commercial Portland cement CEM I $42.5 \mathrm{~N}$, distilled water and two chemically different polymers (in the form of aqueous polymer dispersions); see Table 1 for elasticity constants and [9] for more details on physical properties. A reference cement paste, without polymers, and two polymer-modified cement pastes (modified either by polymer P1 or P2) were produced, with a polymer-to-cement mass ratio amounting to $p / c=0.10$. The water-to-cement ratio of all mixes amounted to $w / c=0.40$ and accounts for both the distilled water and the water added via the polymer dispersion. The tests were carried out at a constant temperature of $20^{\circ} \mathrm{C}$.

Creep testing followed the protocol of Irfan-ul-Hassan et al. [19]. Cylindrical specimens with a diameter of $70 \mathrm{~mm}$ and a height of $300 \mathrm{~mm}$ were produced and subjected, once every hour, to three-minute-long uniaxial compressive creep tests. The test series was started $21 \mathrm{~h}$ after production and finished seven days later. Thus, each specimen was subjected to 168 short-term creep tests. The compressive tests were carried out inside a temperature-controlled chamber at $20^{\circ} \mathrm{C}$. A universal testing machine of type ZwickRoell Z050 was used. Two metal cylinders at the top and the bottom of the specimens ensured uniaxial load introduction; see $[9,19,56]$ for experimental details.

In order to characterize the linear creep behavior, and in order to avoid damage of the specimens, the load levels were chosen to be considerably smaller than the compressive strength at the time instant of testing. As for the plain cement paste reference, the load levels were chosen to be smaller than or equal to $15 \%$ of the compressive strength, whereby the strength was quantified based on the validated multiscale model described in [30]; see Figure 2a. As for the polymer-modified cement pastes, no predictive strength model is available. However, most polymer-modified concretes exhibit a smaller compressive strength than their unmodified counterparts, particularly for $p / c$-ratios larger than $0.05[57,58]$. Therefore, the load levels were chosen to be smaller than or equal to $7.5 \%$ of the compressive strength of the plain cement paste, reached at the same hydration degree; see Figure 2.

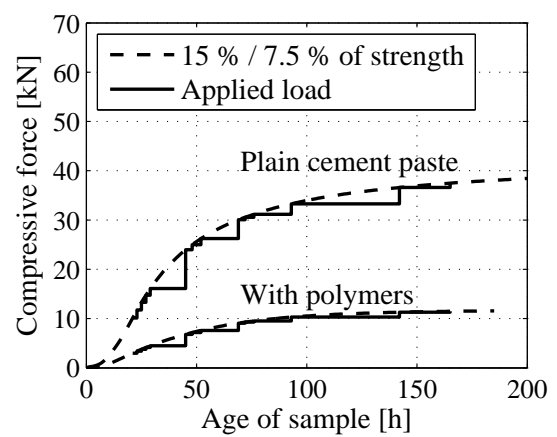

(a)

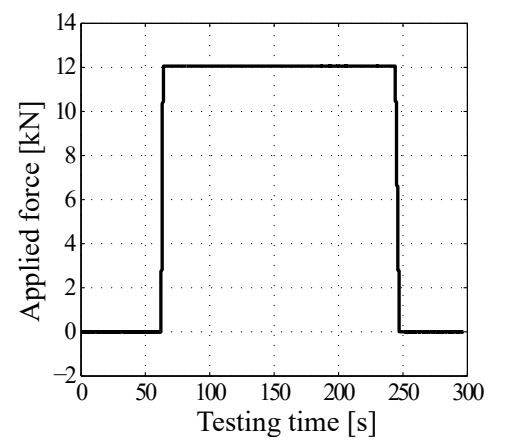

(b)

Figure 2. Compressive loading prescribed during the ultra-short creep tests: (a) prescribed maximum forces applied to the plain and polymer-modified cement pastes; and (b) load history applied to the plain cement paste at an age of $35 \mathrm{~h}$, including a holding plateau with a duration of $180 \mathrm{~s}$.

From the total deformations, measured by means of five inductive displacement transducers (LVDTs), the evolution of the viscous creep strains was quantified, considering that significant creep strains develop already during the very short loading phase, i.e., before reaching the load plateau; see [19] for details. The obtained viscous creep strains of the polymer-modified cement pastes are up to four-times larger than that of the plain paste; see Figure 3. With the increasing degree of hydration, which was measured by means of quasi-isothermal calorimetry [9], the differences between the two modified pastes, on the one hand, and the unmodified paste, on the other hand, decrease. Notably, 
the macroscopic viscous creep strains of the cement paste samples can be perfectly fitted by means of power-law-type creep functions [9], defined as:

$$
J_{v, c p}^{\exp }(t-\tau)=\frac{1}{E_{c, c p}^{\exp }}\left(\frac{t-\tau}{t_{\text {ref }}}\right)^{\beta_{c p}^{\exp }}
$$

where $E_{c, c p}^{\exp }$ and $\beta_{c p}^{\exp }$ denote the cement paste-related creep modulus and the power-law exponent. For the discussion on their evolution with respect to material age and hydration degree, we refer to [9]. Herein, we proceed with top-down identification of the creep properties of the microscopic polymer particles.

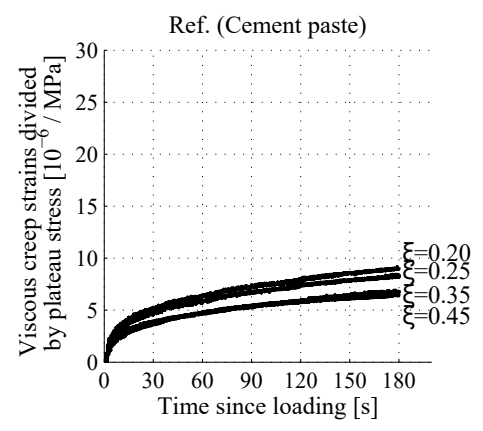

(a)

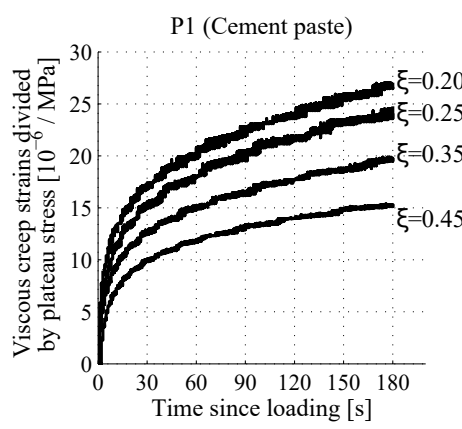

(b)

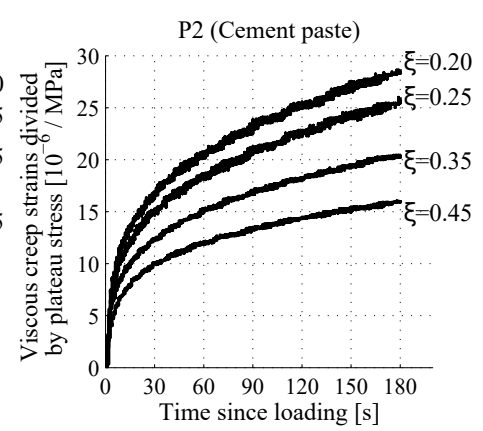

(c)

Figure 3. Results from hourly-repeated three-minute-long creep testing for selected hydration degrees $\xi$ : creep strain evolutions divided by the plateau stress, (a) of the plain cement paste reference with $w / c=0.40$ and $(\mathbf{b}, \mathbf{c})$ of the two polymer-modified cement pastes with $w / c=0.40$ and $p / c=0.10$.

\subsection{Universal Polymer Creep Properties}

As for identifying the creep properties of the microscopic polymer particles, based on the experimentally-determined creep functions (16), we first consider that the polymers exhibit universal creep parameters, i.e., $\mu_{c, \text { pol }}$ and $\beta_{\text {pol }}$ are considered to be age-independent constants. They are identified by minimizing the error between experimentally-determined and model-predicted uniaxial viscous creep function, defined as:

$$
\epsilon=\frac{1}{n_{\tilde{\zeta}} n_{t}} \sum_{i=1}^{n_{\tilde{\xi}}} \sum_{j=1}^{n_{t}}\left|J_{v, c p}^{\bmod }\left(t_{j}\right)-J_{v, c p}^{\exp }\left(t_{k}\right)\right|
$$

where the sum over $n_{\xi}$ accounts for the varying maturity states of the cement pastes (in total, 168 per specimen), $n_{t}$ refers to 180 time steps, with $t_{k} \in[1,180], J_{v, c p}^{\exp }$ denotes the viscous part of the experimentally-determined creep function prescribed in Equation (16) and $J_{v, c p}^{\bmod }$ denotes the model-predicted counterpart. The latter is obtained as the 1111-component of the creep tensor function defined in Equation (15). The optimization problem related to minimizing the mean error $\epsilon$ according to Equation (17) is solved, independently for both polymer-modified mixes, using the Nelder-Mead algorithm and results in optimal (universal) creep parameters, reading as:

$$
\begin{array}{ll}
\mu_{c, \mathrm{P} 1}=0.609 \mathrm{GPa}, & \beta_{P 1}=0.143, \\
\mu_{c, \mathrm{P} 2}=0.616 \mathrm{GPa}, & \beta_{P 2}=0.216 .
\end{array}
$$

The respective mean error amounts to $1.7 \times 10^{-6} / \mathrm{MPa}$ for the cement paste modified with polymer P1 and to $1.9 \times 10^{-6} / \mathrm{MPa}$ for the cement paste modified with polymer P2. The optimal universal shear creep moduli of the polymers are by two orders of magnitude lower than the one of 
the hydrates; compare Equation (18) with Equation (6). The identified polymer creep properties allow for a quite reliable (but clearly not perfect) reproduction of the experimentally-determined viscous strains; see Figure 4. This demonstrates that the experimentally-observed significantly larger creep activity of the polymer-modified cement pastes, relative to the unmodified reference paste, can be traced back to the creep behavior of the micrometer-sized polymer particles, despite their relatively small volume fraction.

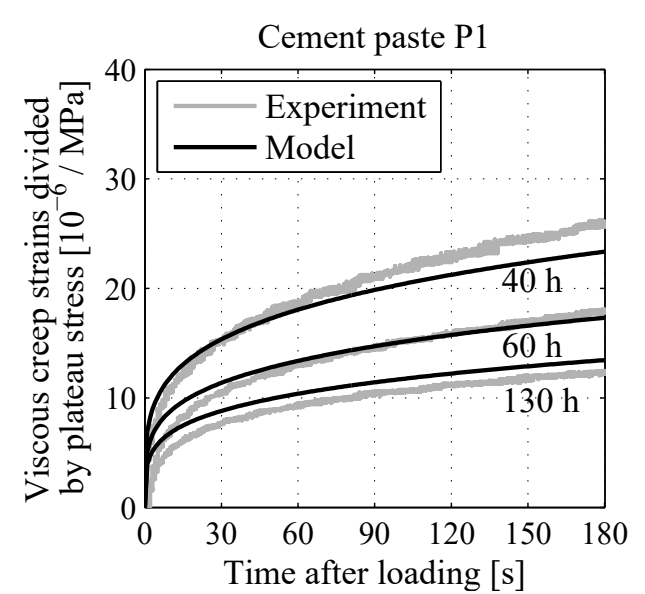

(a)

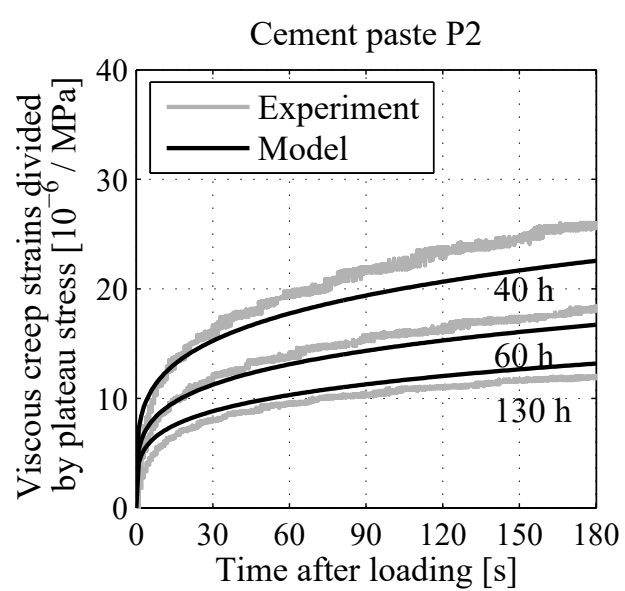

(b)

Figure 4. Comparison of experimentally-determined and model-predicted viscous strains of polymer-modified cement pastes P1 (a) and P2 (b) at material ages of $40 \mathrm{~h}, 60 \mathrm{~h}$ and $130 \mathrm{~h}$ for constant polymer creep properties.

\subsection{Age-Dependent Polymer Creep Properties}

Creep tests on macroscopic polymer specimens revealed that the creep activity of polymers decreases with decreasing relative humidity to which the polymers are exposed [59-61]. The polymers within the cement pastes are also exposed to considerable decreases of the internal relative humidity, resulting from self-desiccation, i.e., from the water-consuming hydration reaction. Lura et al. [62] showed that the internal relative humidity in a cement paste sample with $w / c=0.37$ decreased, within the first few days after mixing, from $98 \%$ to $92 \%$. Notably, the resulting capillary pressure increased virtually linearly with the hydration degree $\xi$, in the regime $\xi>30 \%$; see [22]. As for mortars and concretes, the self-desiccation-induced capillary underpressure was shown to result in water migration from the open porosity of the aggregates into the cement paste matrix [22]. A similar mechanism is envisaged to reduce the water content of the polymers. This motivates us to consider that the creep properties of polymer phases are age-dependent. In the following, it is investigated if the reproduction quality of the multiscale model can be significantly improved, provided that age-dependent polymer creep properties are considered. In this context, two different identification strategies are implemented: (i) only the shear creep modulus is considered to be age-dependent, while the power-law exponent is considered to be constant, and (ii) both the shear creep modulus and the power-law exponent are considered to be age-dependent.

As for the first identification strategy, different amplitudes of the constant power-law exponent are considered: $\beta_{\text {pol }} \in\{0.1,0.3,0.4,0.5,0.6,0.7,0.8,0.9,1.1,1.3\}$. For each one of these values, all 168 creep tests are analyzed, in order to identify optimal values of shear creep moduli that minimize the error between experimental and modeled viscous creep functions. Interestingly, the obtained total mean errors, according to Equation (17), are virtually constant for power-law exponents within the interval $\beta_{\mathrm{pol}} \in[0.4,0.8]$; see Figure 5. As for the further steps of the analysis, we choose the central value $\beta_{P 1}=\beta_{P 2}=0.6$. The corresponding mean errors amount to $2.7 \times 10^{-7} / \mathrm{MPa}$ for paste $\mathrm{P} 1$ and to $2.9 \times 10^{-7} / \mathrm{MPa}$ for paste P2. Remarkably, (i) these mean errors are one order of magnitude smaller than the mean errors obtained under the consideration of constant polymer creep properties (see also 
Table 2), and (ii) the corresponding modeled creep strains agree very well with the experimental data (see Figure 6). This underlines that the creep activity of polymers in hydrating cement paste might indeed change and that the decreasing relative humidity results in a decrease of the polymer creep behavior.

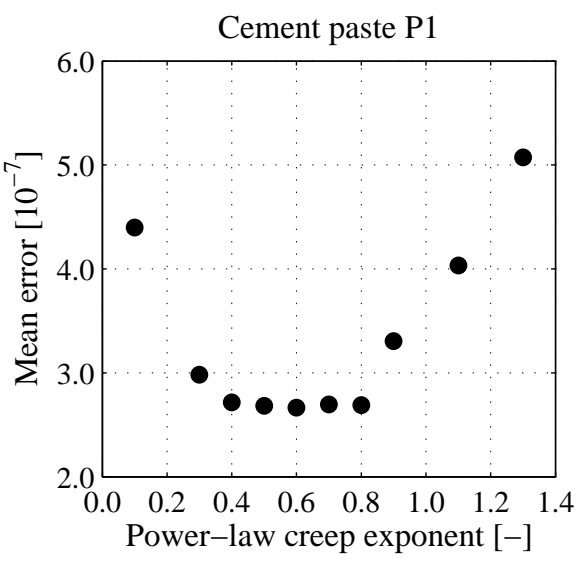

(a)

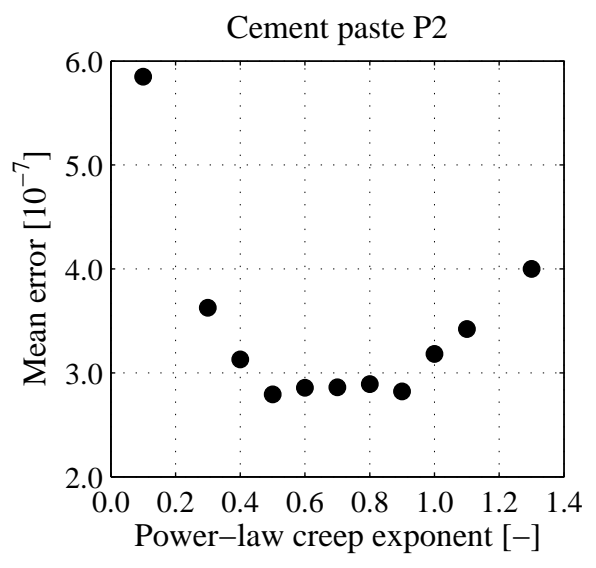

(b)

Figure 5. Mean errors according to Equation (17) for age-independent power-law creep exponents within $\beta_{p o l} \in\{0.1,0.3,0.4,0.5,0.6,0.7,0.8,0.9,1.1,1.3\}$ and for optimized age-dependent shear creep moduli for paste P1 (a) and paste P2 (b).

Table 2. Mean errors $\epsilon$ according to Equation (17) for universal and age-dependent polymer creep properties.

\begin{tabular}{cccc}
\hline Shear Creep Modulus & Power-Law Creep Exponent & Polymer & Mean Error $\epsilon$ \\
\hline universal & universal & P1 & $1.709 \times 10^{-6}$ \\
universal & universal & P2 & $1.927 \times 10^{-6}$ \\
\hline age-dependent & universal & P1 & $2.665 \times 10^{-7}$ \\
age-dependent & universal & P2 & $2.857 \times 10^{-7}$ \\
\hline age-dependent & age-dependent & P1 & $1.975 \times 10^{-7}$ \\
age-dependent & age-dependent & P2 & $2.227 \times 10^{-7}$ \\
\hline
\end{tabular}

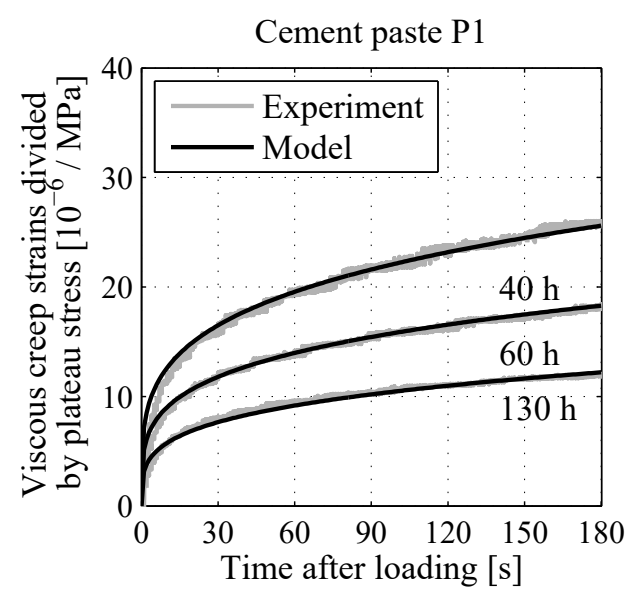

(a)

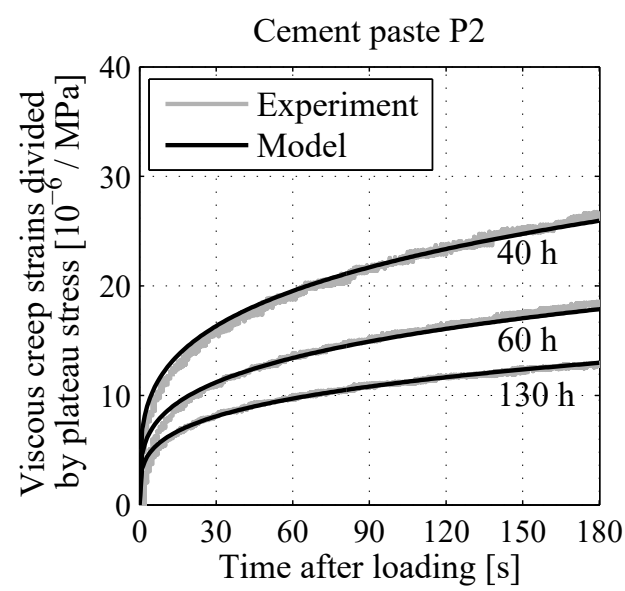

(b)

Figure 6. Comparison of experimental and computed creep strains of polymer-modified cement pastes P1 (a) and P2 (b) at ages of $40 \mathrm{~h}, 60 \mathrm{~h}$ and $130 \mathrm{~h}$, considering age-dependent shear creep moduli and constant power-law creep exponents. 
The identified shear creep moduli increase, in a virtually bilinear fashion, with increasing material age; see Figure 7. For material ages up to $40 \mathrm{~h}$, the identified shear creep moduli increase quite rapidly up to $\mu_{c, P 1} \approx 0.10 \mathrm{GPa}$ and $\mu_{c, P 2} \approx 0.14 \mathrm{GPa}$, respectively. Thereafter, the hourly increase is significantly smaller. After one week of hydration, the identified values amount to $\mu_{c, P 1} \approx 0.23 \mathrm{GPa}$ and $\mu_{c, P 2} \approx 0.26 \mathrm{GPa}$, respectively.

The progressive decrease of the internal relative humidity is, on the one hand, a prime candidate for explaining the decrease of the creep activity of the polymers, but on the other hand, it is difficult to imagine how it could explain the obtained bilinear evolution of the identified creep shear moduli. Therefore, a second microstructural effect appears to be involved. Tian et al. [36] observed that the polymer particles are not uniformly distributed throughout the microstructure at the time instant of casting. Instead, the polymer particles flocculate, referred to as localization. One might speculate that such polymer agglomerates exhibit a much more compliant time-dependent behavior compared to the individual polymer particles. According to Tian et al. [36], the growing hydrates penetrate into the flocculated polymer particles, such that the agglomerates are progressively destroyed. Bijen and Su [63] and Dimmig-Osburg [64] among others also observed that the cementitious hydration products grow through the polymer layers by means of ESEM investigations. The first and strongly increasing branch of the time-evolution of the shear creep modulus might reflect this progressive destruction of polymer agglomerates, but clearly there is a need for more experimental evidence, before a convincing conclusion could be drawn.

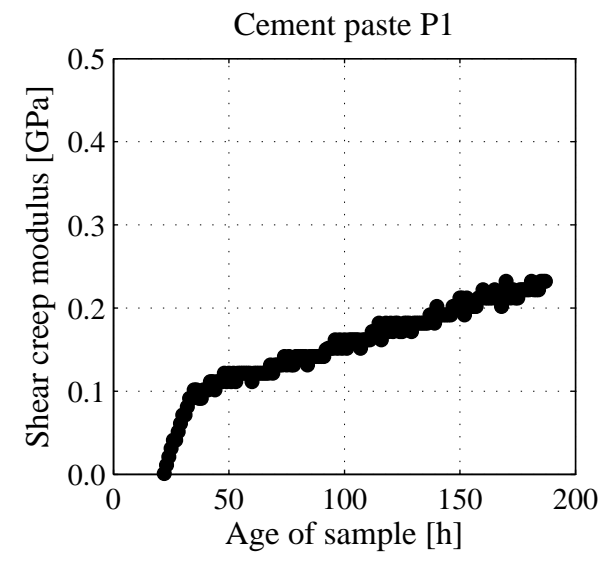

(a)

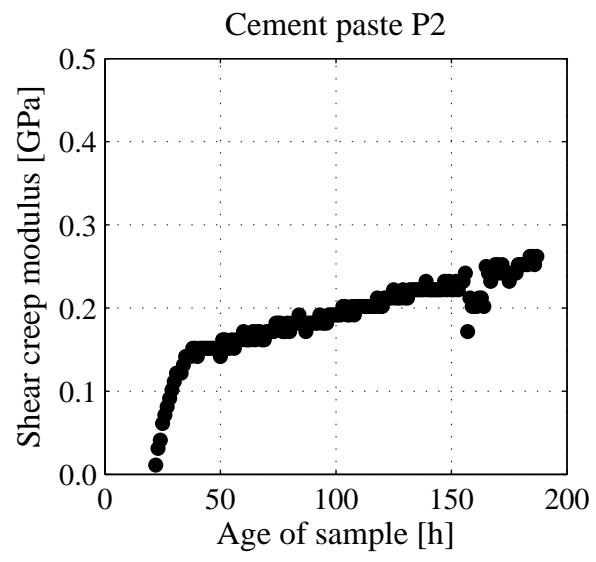

(b)

Figure 7. Evolutions of the shear creep modulus with respect to material age, while considering time-independent power-law exponents $\beta_{P 1}=\beta_{P 2}=0.6$, for paste P1 (a) and paste P2 (b).

As for the second identification strategy, all 168 tests per specimen are reanalyzed, and optimal values of both the creep shear modulus and the power-law creep exponent are identified simultaneously, so as to minimize the error between modeled and measured creep strains. In other words, both the creep shear modulus and the power-law creep exponent are considered to be age-dependent and, thus, evolving quantities. The identified shear creep moduli and the identified power-law creep exponents evolve nonlinearly with increasing material age; see Figure 8. In comparison with Figure 7, the evolutions of the shear creep modulus, as well as of the power-law exponent exhibit a more pronounced scatter. Most likely, this is related to the more complex optimization problem of the second identification strategy, which involves the determination of two variables. Therewith, the two variables may span an area with several minimal values close to each other, rendering the identification of the optima more challenging. After a rather rapid increase of the shear creep modulus up to material ages of about $40 \mathrm{~h}$, it is almost constant between ages of 40 and $110 \mathrm{~h}$ and amounts to $\mu_{c, P 1} \approx 0.08 \mathrm{GPa}$ and $\mu_{c, P 2} \approx 0.11 \mathrm{GPa}$, respectively. Thereafter, the shear creep modulus increases again rather rapidly and reaches, one week after production, $\mu_{c, P 1} \approx 0.60 \mathrm{MPa}$ 
and $\mu_{c, P 2} \approx 0.40 \mathrm{MPa}$, respectively. The power-law creep exponents, in turn, are virtually constant, $\beta_{P 1} \approx \beta_{P 2} \approx 0.9$, at material ages of less than $100 \mathrm{~h}$. Subsequently, they decrease and finally stabilize around $\beta_{P 1} \approx 0.3$ or $\beta_{P 2} \approx 0.4$, respectively. The corresponding mean errors, according to (17), amount to $2.0 \times 10^{-7}$ for paste P1 and $2.2 \times 10^{-7}$ for paste P2. These values are approximately $25 \%$ smaller compared to that obtained with a constant power-law exponent; see Table 2 . The experimentally-measured creep strains are, therefore, reproduced even more accurately; see Figure 9.

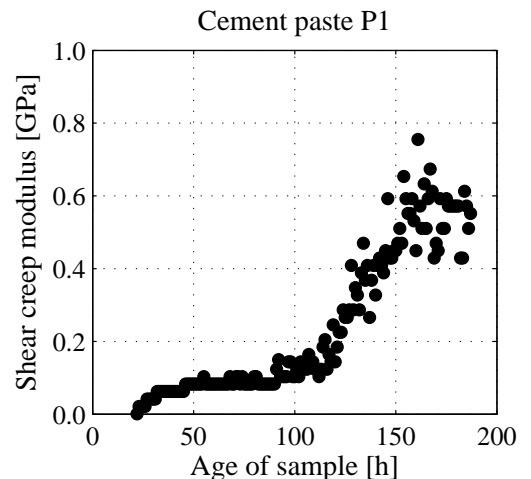

(a)

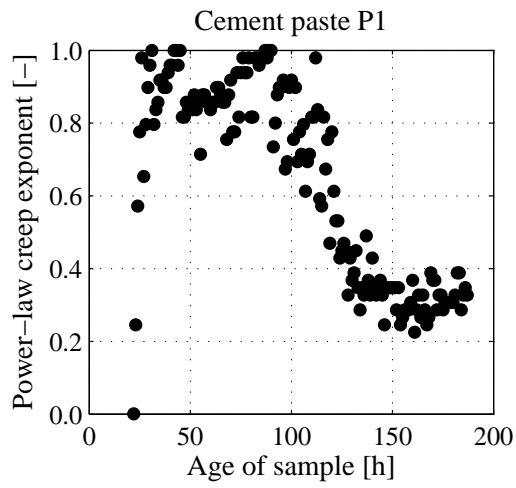

(c)

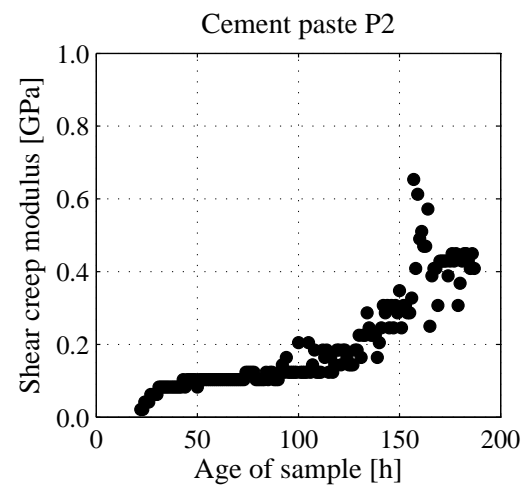

(b)

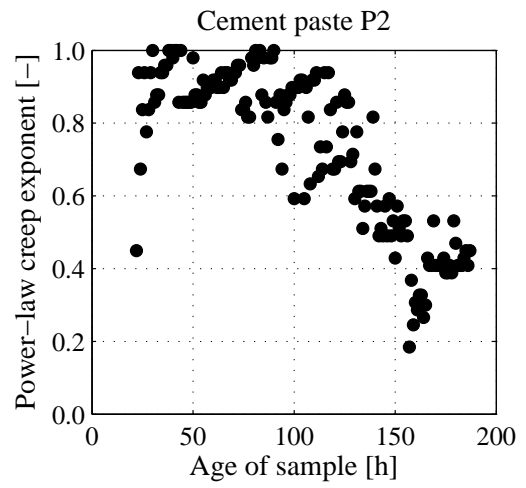

(d)

Figure 8. Evolutions of the shear creep modulus and the power-law creep exponent with respect to material age, for paste $\mathrm{P} 1(\mathbf{a}, \mathbf{c})$ and paste $\mathrm{P} 2(\mathbf{b}, \mathbf{d})$.

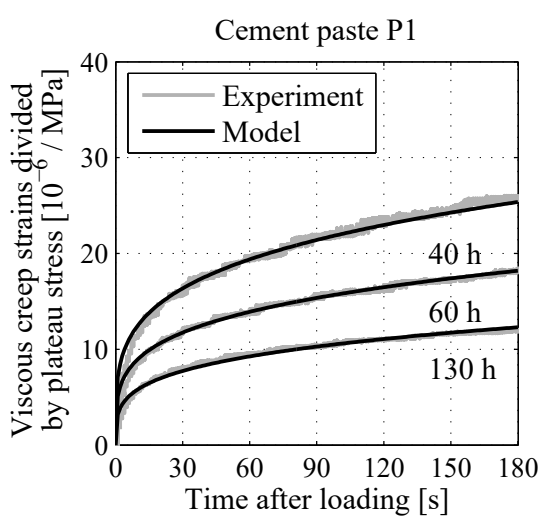

(a)

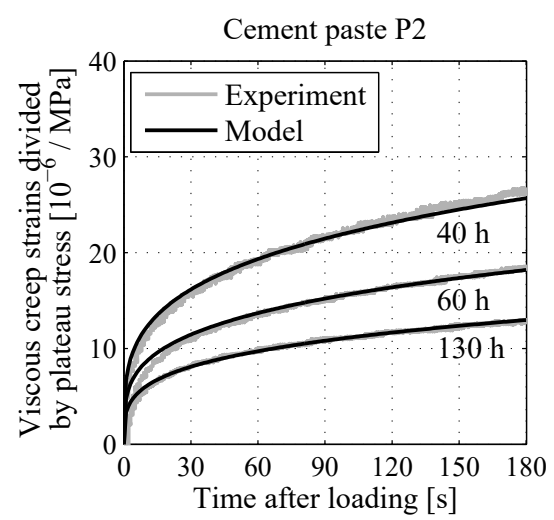

(b)

Figure 9. Comparison of experimental and computed creep strains of polymer-modified cement pastes P1 (a) and P2 (b) at ages of $40 \mathrm{~h}, 60 \mathrm{~h}$ and $130 \mathrm{~h}$, considering both age-dependent shear creep moduli and age-dependent power-law creep exponents. 


\section{Conclusions}

A micromechanics-based multiscale model for creep homogenization of polymer-modified cement pastes was developed herein. It was used to investigate the micromechanical origin of the pronounced macroscopic creep activity of such cement pastes. To this end, the microscopic polymer particles were considered to show a power-law-type creep behavior. Based on micro-to-macro-scale-transition relations, developed in the framework of continuum micromechanics, the viscoelastic behavior of the microscopic polymer particles was linked to the macroscopic creep behavior of cement paste. By means of a top-down identification approach, we exploited results from a comprehensive macroscopic early-age creep testing campaign [9], involving 168 short-term creep tests on two polymer-modified cement paste mixes. From the obtained results, the following conclusions are drawn.

- The pronounced creep activity of polymer-modified cement paste can be explained by an isochoric power-law-type creep behavior of the polymers, whereby the shear creep modulus of the polymers is two orders of magnitude smaller than that of the hydrates.

- The creep behavior of the polymer particles inside hydrating cement paste is not universal. The creep activity of the polymer particles decreases significantly as hydration proceeds. The underlying physical mechanism is very likely related (i) to self-desiccation resulting from the (water-consuming) hydration reaction and (ii) to the associated continuous decrease of the internal relative humidity in cement pastes [62].

- The experimentally-observed macroscopic creep behavior of hydrating polymer-modified cement pastes can be satisfactorily reproduced when considering that the power-law creep exponent of the polymer particles is age-independent and, thus, constant. In that case, the shear creep modulus of the polymer particles was found to follow a bilinear trend during the first week after production. Considering that both the shear creep modulus and the creep exponent of the polymers are age-dependent and, thus, evolving functions, the agreement between modeling results and experiments can be further improved, but at the cost of considerable additional computational efforts.

- As for future research regarding the viscoelastic behavior of polymer-modified cement pastes, it is desirable to monitor the evolution of the internal relative humidity. This will provide the necessary physical background to interpret the self-desiccation-induced changes of the creep behavior of the polymers.

Acknowledgments: This research is supported by the German Research Foundation (DFG) via the Research Training Group "Evaluation of Coupled Numerical and Experimental Partial Models in Structural Engineering (GRK 1462)" which is gratefully acknowledged. This work was further supported by a short-term scientific mission (STSM) Grant from COST Action TU 1404 "Towards the next generation of standards for service life of cement-based materials and structures".

Author Contributions: Bernhard Pichler set up the overall strategies for experimental testing, measurement evaluation and the multiscale modeling within the framework of continuum micromechanics. He supervised the research progress, checked key results and supported the documentation process. Luise Göbel produced the specimens and carried out the hourly-repeated three-minute-long creep tests, supported by the technical staff of the laboratory. She developed MATLAB codes for the evaluation of the measurement data, as well as for the two-scale creep homogenization of polymer-modified cementitious materials. She also carried out the model validation based on the test data and documented the research results. Markus Königsberger developed the Maple code for the Laplace-Carson transform, contributed to both the discussion processes and the documentation of the research results and helped with proof reading the paper. Andrea Osburg supervised the research process, checked key results and supported the documentation process.

Conflicts of Interest: The authors declare no conflict of interest. The founding sponsors had no role in the design of the study; in the collection, analyses or interpretation of data; in the writing of the manuscript; nor in the decision to publish the results. 


\section{Abbreviations}

The following abbreviations and symbols are used in this manuscript:

$\mathbb{C}_{j} \quad$ elastic stiffness tensor of phase $j$

clin cement

cp cement paste

cyl cylindrical

$E_{c, c p}^{\exp } \quad$ experimentally-determined creep modulus of cement paste

exp experimentally-determined

$f_{j}^{h f} \quad$ hydrate foam-related volume fraction of phase $j$

$f_{j}^{c p} \quad$ cement paste-related volume fraction of phase $j$

hyd hydrates

hf hydrate foam

$\mathbb{I} \quad$ fourth-order identity tensor

$\mathbb{I}^{\mathrm{vol}}, \mathbb{I}^{\mathrm{dev}} \quad$ volumetric and deviatoric parts of the fourth-order identity tensor

$J_{c p}^{\exp }, J_{c p}^{\exp }$ experimentally-determined and model-predicted uniaxial creep function of cement paste

$J_{v, c p}^{\exp }, J_{v, c p}^{\exp } \quad$ viscous parts of $J_{c p}^{\exp }, J_{c p}^{\exp }$

$\mathbb{J} \quad$ fourth-order creep tensor function

$k_{j} \quad$ bulk modulus of phase $j$

mod model-predicted

P1, P2 Polymer 1, Polymer 2

$p \quad$ complex variable in the LC domain

$\mathbb{P}_{m} \quad$ Hill tensor with shape $m, m \in\{$ cyl, sph $\}$

pol polymer

$\mathbb{R} \quad$ fourth-order relaxation tensor function

$\mathbb{S} \quad$ fourth-order Eshelby tensor

sph spherical

$t \quad$ chronological time

$t_{\text {ref }} \quad$ reference time

$\beta_{j} \quad$ power-law creep exponent of phase $j$

$\beta_{c p}^{\exp } \quad$ experimentally-determined power-law exponent of cement paste

$\Gamma \quad$ gamma function

$\delta \quad$ Kronecker delta

$\varepsilon_{j} \quad$ strain of phase $j$

$\vartheta \quad$ zenith angle

$\mu_{j} \quad$ shear modulus of phase $j$

$\mu_{c, j} \quad$ shear creep modulus of phase $j$

$\xi \quad$ degree of hydration

$\sigma_{j} \quad$ stress of phase $j$

$\tau \quad$ time instant of loading

$\varphi \quad$ azimuth angle

$(\bullet)^{*} \quad$ LC transform of quantity $(\bullet)$

\section{Appendix A. Phase Volume Fractions}

The phase volume fractions introduced in Equations (13) and (14), namely the "hydrate foam"-related volume fractions, $f_{j}^{h f}$, and the "cement paste"-related volume fractions, $f_{j}^{c p}$, are functions of the mix design, as expressed by means of (initial) water-to-cement mass ratio $w / c$ and (initial) solid polymer-to-cement mass ratio $p / c$ and the maturity state of the material, expressed by means of the degree of hydration $\xi$. Herein, we consider that the polymer volume fraction remains constant throughout the hydration process given they do not alter the nature of the hydration process and only change, due to adsorption and complexation mechanisms, its kinetics $[65,66]$. This way, the volume fraction of the polymer phase can be quantified based on the mix design. Denoting the initial masses of cement, water and the polymer as $c, w$ and $p$, respectively, and their mass densities as 
$\rho_{\mathrm{cem}}, \rho_{\text {water }}$ and $\rho_{\text {pol }}$ (quantitative values are given in Table 1 , the cement paste-related volume fraction of the polymer reads as [9]:

$$
f_{\text {pol }}^{c p}=\frac{V_{\text {pol }}}{V_{\text {cem }}+V_{\text {water }}+V_{\text {pol }}}=\frac{\frac{p}{\rho_{\text {pol }}}}{\frac{c}{\rho_{\text {cem }}}+\frac{w}{\rho_{\text {water }}}+\frac{p}{\rho_{\text {pol }}}}=\frac{(p / c) \frac{\rho_{\text {water }}}{\rho_{\text {pol }}}}{\frac{\rho_{\text {water }}}{\rho_{\text {cem }}}+(w / c)+(p / c) \frac{\rho_{\text {water }}}{\rho_{\text {pol }}}} .
$$

The cement paste-related volume fractions of the other material phases (cement, capillary pore, and hydrate gel) follow from Powers' hydration model [41,51] and the consideration of the additional polymers as:

$$
\begin{aligned}
f_{\mathrm{cem}}^{c p} & =\frac{20(1-\xi)}{20+63(w / c)}\left(1-f_{\mathrm{pol}}^{c p}\right) \geq 0, \\
f_{\mathrm{por}}^{c p} & =\frac{63[(w / c)-0.367 \xi]}{20+63(w / c)}\left(1-f_{\mathrm{pol}}^{c p}\right) \geq 0, \\
f_{\text {hyd }}^{c p} & =\frac{43.15 \xi}{20+63(w / c)}\left(1-f_{\mathrm{pol}}^{c p}\right)
\end{aligned}
$$

See Figure A1 for an illustration.

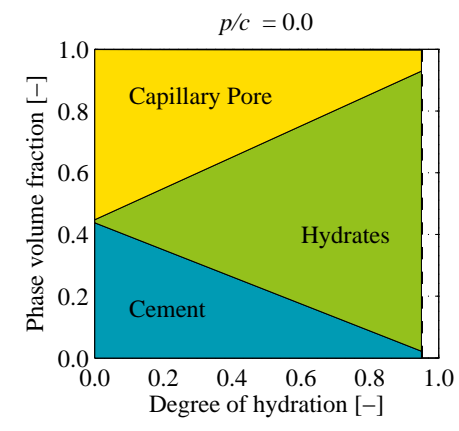

(a)

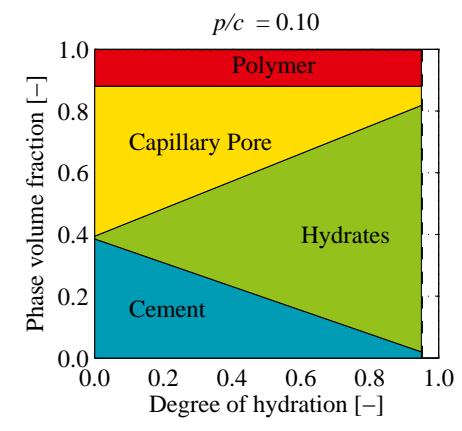

(b)

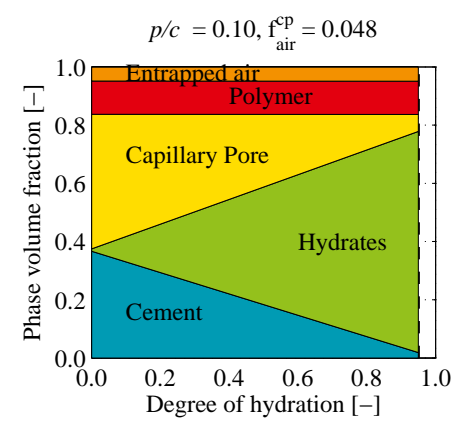

(c)

Figure A1. Evolution of "cement paste"-related phase volume fractions as a function of the hydration degree for (a) plain cement paste with $w / c=0.40$, for (b) polymer-modified cement paste with $w / c=0.40, p / c=0.10$ and for (c) polymer-modified cement paste with $w / c=0.40, p / c=0.10$, and $f_{\text {air }}^{c p}=0.048$.

The phase volume fractions at the scale of the hydrate foam, in turn, follow as [29]:

$$
f_{j}^{h f}=\frac{f_{j}^{c p}}{1-f_{\mathrm{cem}}^{c p}}, \quad j \in\{\text { hyd, por, pol }\} .
$$

The hydration model of Powers is further extended for polymer-modified cement pastes that exhibit entrapped air porosity $f_{\text {air }}^{c p}$. Then, the calculation of the "cement paste-related" volume fractions of the cement and the hydrate foam matrix is extended to include entrapped air $f_{\text {air }}^{c p}$ additionally:

$$
f_{\mathrm{hf}}^{c p}+f_{\mathrm{cem}}^{c p}+f_{\text {air }}^{c p}=1 .
$$

The volume fractions of the cement and the hydrate foam at the cement paste scale are derived as:

$$
\begin{aligned}
f_{\mathrm{cem}}^{c p} & =\frac{20(1-\xi)}{20+63(w / c)}\left(1-f_{\mathrm{pol}}^{c p}\right)\left(1-f_{\text {air }}^{c p}\right), \\
f_{\mathrm{hf}}^{c p} & =1-f_{\text {air }}^{c p}-f_{\mathrm{cem}}^{c p} .
\end{aligned}
$$


The amount of entrapped air is estimated based on the macroscopic bulk densities of the cement pastes, which are determined after demolding, at material ages of $20 \mathrm{~h}$. For the plain reference paste, the bulk density is equal to $1.99 \mathrm{~g} \mathrm{~cm}^{-3}$. The cement paste P1 exhibits a bulk density of $1.88 \mathrm{~g} \mathrm{~cm}^{-3}$. The reduction refers to the added polymer whose density is smaller compared to the cementitious components. The density of paste P2 is even more reduced and amounts to $1.79 \mathrm{~g} \mathrm{~cm}^{-3}$, which is related to the higher fraction of entrapped air. Supposedly, paste P1 does not contain entrapped air. Then, comparing the bulk densities of the two polymer-modified cement pastes yields the volume fraction of entrapped air porosity in the cement paste $\mathrm{P} 2, f_{\text {air }}^{c p}=4.8 \%$.

\section{Appendix B. Hill Tensor Expressions in the LC Space}

As for upscaling of the viscoelastic behavior of the polymer and hydrate phases to the cement paste scale, according to Equations (13) and (14), expressions for the LC transformed Hill tensors $\mathbb{P}_{m}^{h f, *}(p)$ for spherical $(m=\mathrm{sph})$ and cylindrical inclusions $(m=$ cyl) embedded in an infinite hydrate foam matrix are required. They read as:

$$
\mathbb{P}_{m}^{h f, *}(p)=\mathbb{S}_{m}^{h f, *}(p):\left[\mathbb{R}_{h f}^{*}(p)\right]^{-1} \cdot \quad m \in\{\text { sph, cyl }\},
$$

where $\mathbb{S}_{m}^{h f, *}(p)$ is the LC transformed Eshelby tensor of the corresponding inclusion phase (either the spherical phases cement and entrapped air, capillary pores or polymers, respectively, or the cylindrical hydrate phase) and $\mathbb{R}_{h f}^{*}$ is the LC transformed relaxation function of the hydrate foam matrix phase. The LC transformed Eshelby tensor of a spherical inclusion is isotropic and may be decomposed as:

$$
\mathbb{S}_{m}^{h f, *}(p)=S_{\mathrm{sph}}^{h f, *, \mathrm{vol}} \mathbb{I}^{v o l}+S_{\mathrm{sph}}^{h f, *, \operatorname{dev}} \mathbb{I}^{d e v}
$$

with volumetric and deviatoric components reading as [49]:

$$
S_{\mathrm{sph}}^{h f, *, \mathrm{vol}}(p)=\frac{3 k_{h f}^{*}(p)}{3 k_{h f}^{*}(p)+4 \mu_{h f}^{*}(p)}, \quad S_{\mathrm{sph}}^{h f, *, \operatorname{dev}}(p)=\frac{6}{5} \frac{k_{h f}^{*}(p)+2 \mu_{h f}^{*}(p)}{3 k_{h f}^{*}(p)+4 \mu_{h f}^{*}(p)},
$$

where $k_{h f}^{*}$ and $\mu_{h f}^{*}$ denote LC transformed bulk and shear moduli of the hydrate foam. As for a cylindrical hydrate inclusion oriented in the $\underline{e}_{3}$ direction, the nonzero components of the LC transformed Hill tensors read as [33]

$$
\begin{aligned}
& \mathbb{S}_{\mathrm{cyl}, 1111}^{h f, *}(p)=\mathbb{S}_{\mathrm{cyl}, 2222}^{h f, *}=\frac{9}{4} \frac{k_{h f}^{*}(p)+\mu_{h f}^{*}(p)}{3 k_{h f}^{*}(p)+4 \mu_{h f}^{*}(p)}, \\
& \mathbb{S}_{\mathrm{cyl}, 1122}^{h f, *}(p)=\mathbb{S}_{\mathrm{cyl}, 2211}^{h f, *}=\frac{1}{4} \frac{3 k_{h f}^{*}(p)-5 \mu_{h f}^{*}(p)}{3 k_{h f}^{*}(p)+4 \mu_{h f}^{*}(p)}, \\
& \mathbb{S}_{\mathrm{cyl}, 1133}^{h f, *}(p)=\mathbb{S}_{\mathrm{cyl}, 2233}^{h f, *}=\frac{1}{2} \frac{3 k_{h f}^{*}(p)-2 \mu_{h f}^{*}(p)}{3 k_{h f}^{*}(p)+4 \mu_{h f}^{*}(p)}, \\
& \mathbb{S}_{\mathrm{cyl}, 1212}^{h f, *}(p)=\frac{1}{4} \frac{3 k_{h f}^{*}(p)+7 \mu_{h f}^{*}(p)}{3 k_{h f}^{*}(p)+4 \mu_{h f}^{*}(p)^{\prime}} \\
& \mathbb{S}_{\mathrm{cyl}, 1313}^{h f, *}(p)=\mathbb{S}_{\mathrm{cyl}, p, 2323}^{\mathrm{Esh}}=\frac{1}{4} .
\end{aligned}
$$

The tensor $\mathbb{S}_{\mathrm{cyl}}^{h f, *}$ exhibits the following symmetries $\mathbb{S}_{\mathrm{cyl}, i j k l}^{h f, *}=\mathbb{S}_{\mathrm{cyl}, j i k l}^{h f, *}=\mathbb{S}_{\mathrm{cyl}, i j l k}^{h f, *}=\mathbb{S}_{\mathrm{cyl}, j i l k}^{h f, *}$ 


\section{References}

1. Dimmig-Osburg, A. Innovations Based on PCC. Adv. Mater. Res. 2013, 687, 369-377.

2. Kim, D.G.; Lee, D.U.; Yang, E.I.; Cha, H. Durability of latex-modified concrete carried by ready-mix truck for concrete rooftops. Mag. Concr. Res. 2016, 68, 318-324.

3. Guo, Y.; Shen, A.; Shun, X. Exploring Polymer-Modified Concrete and Cementitious Coating with High-Durability for Roadside Structures in Xinjiang, China. Adv. Mater. Sci. Eng. 2017, 2017, 9425361.

4. Ohama, Y. Polymer-based Admixtures. Cem. Concr. Compos. 1998, 20, 189-212.

5. Bureau, L.; Alliche, A.; Pilvin, P.; Pascal, S. Mechanical characterization of a styrene-butadiene modified mortar. Mater. Sci. Eng. A 2001, 308, 233-240.

6. Al-Zahrani, M.M.; Maslehuddin, M.; Al-Dulaijan, S.U.; Ibrahim, M. Mechanical properties and durability characteristics of polymer- and cement-based repair materials. Cem. Concr. Compos. 2003, 25, 527-537.

7. Choi, P.; Yun, K.K. Experimental analysis of latex-solid content effect on early-age and autogenous shrinkage of very-early strength latex-modified concrete. Constr. Build. Mater. 2014, 65, 396-404.

8. Göbel, L.; Pichler, B.; Osburg, A. Early-age experimental characterization and semi-analytical modeling of elasticity and creep of polymer-modified cement pastes. In Proceedings of the Second International RILEM Conference on Early-Age Cracking and Serviceability in Cement-Based Materials and Structures, Brussels, Belgium, 12-14 September 2017.

9. Göbel, L.; Pichler, B.; Osburg, A. The mechanical performance of polymer-modified cement pastes at early ages: Ultra-short non-aging creep tests and multiscale homogenization. Constr. Build. Mater. 2018, in press.

10. Ito, M.; Aoki, S.; Hirata, T.; Hayakawa, K.; Abe, H.; Tottri, S. Development of high quality patching method by applying wet spraying, using polymer cement mortar and set accelerating agent. JSCE J. Constr. Eng. Manag. 2006, 62, 459-472.

11. Lee, J.H.; Kim, H.H.; Park, S.K.; Oh, R.O.; Kim, H.D.; Park, C.G. Mechanical Properties and Durability of Latex-Modified Fiber-Reinforced Concrete: A Tunnel Liner Application. Adv. Mater. Sci. Eng. 2018, 2018, 1-14.

12. Sercombe, J.; Hellmich, C.; Ulm, F.J.; Mang, H.A. Modeling of early-age creep of shotcrete. I: Model and Model Parameters. J. Eng. Mech. 2000, 126, 284-291.

13. Ullah, S.; Pichler, B.; Scheiner, S.; Hellmich, C. Shell-specific interpolation of measured 3D displacements, for micromechanics-based rapid safety assessment of shotcrete tunnels. Comput. Model. Eng. Sci. 2010, 57, 279-314.

14. Woolson, I.H. Some remarkable tests indicating flow of concrete under pressure. Eng. News 1905, 54, 459-460.

15. Hatt, W.K. Notes on the effect of time element in loading reinforced concrete beams. Proc. ASTM 1907, 7, 421-433.

16. Bažant, Z.P.; Li, G.H. Comprehensive database on concrete creep and shrinkage. ACI Mater. J. 2008, 105, 635-637.

17. Boulay, C.; Staquet, S.; Delsaute, B.; Carette, J.; Crespini, M.; Yazoghli-Marzouk, O.; Merliot, É.; Ramanich, S. How to monitor the modulus of elasticity of concrete, automatically since the earliest age? Mater. Struct. 2014, 47, 141-155.

18. Karte, P.; Hlobil, M.; Reihsner, R.; Dörner, W.; Lahayne, O.; Eberhardsteiner, J.; Pichler, B. Unloading-Based Stiffness Characterisation of Cement Pastes During the Second, Third and Fourth Day After Production. Strain 2015, 51, 156-169.

19. Irfan-ul Hassan, M.; Pichler, B.; Reihsner, R.; Hellmich, C. Elastic and creep properties of young cement paste, as determined from hourly repeated minute-long quasi-static tests. Cem. Concr. Res. 2016, 82, 36-49.

20. Delsaute, B.; Boulay, C.; Staquet, S. Creep testing of concrete since setting time by means of permanent and repeated minute-long loadings. Cem. Concr. Compos. 2016, 73, 75-88.

21. Delsaute, B.; Boulay, C.; Granja, J.; Carette, J.; Azenha, M.; Dumoulin, C.; Karaiskos, G.; Deraemaeker, A.; Staquet, S. Testing Concrete E-modulus at Very Early Ages Through Several Techniques: An Inter-laboratory Comparison. Strain 2016, 52, 91-109.

22. Irfan-ul Hassan, M.; Königsberger, M.; Reihsner, R.; Hellmich, C.; Pichler, B. How Water-Aggregate Interactions Affect Concrete Creep: A Multiscale Analysis. J. Nanomech. Micromech. 2017, 7, 4017019.

23. Bernard, O.; Ulm, F.J.; Lemarchand, E. A multiscale micromechanics-hydration model for the early-age elastic properties of cement-based materials. Cem. Concr. Res. 2003, 33, 1293-1309. 
24. Hellmich, C.; Mang, H. Shotcrete Elasticity Revisited in the Framework of Continuum Micromechanics: From Submicron to Meter Level. J. Mater. Civil Eng. 2005, 17, 246-256.

25. Sanahuja, J.; Dormieux, L.; Chanvillard, G. Modelling elasticity of a hydrating cement paste. Cem. Concr. Res. 2007, 37, 1427-1439.

26. Pichler, B.; Hellmich, C.; Eberhardsteiner, J. Spherical and acicular representation of hydrates in a micromechanical model for cement paste: Prediction of early-age elasticity and strength. Acta Mech. 2009, 203, 137-162.

27. Pichler, B.; Scheiner, S.; Hellmich, C. From micron-sized needle-shaped hydrates to meter-sized shotcrete tunnel shells: Micromechanical upscaling of stiffness and strength of hydrating shotcrete. Acta Geotech. 2008, 3, 273-294.

28. Göbel, L.; Bos, C.; Schwaiger, R.; Flohr, A.; Osburg, A. Micromechanics-based prediction of the elastic properties of polymer-modified cementitious materials using nanoindentation and semi-analytical modeling. Cem. Concr. Compos. 2018, 88, 100-114.

29. Pichler, B.; Hellmich, C. Upscaling quasi-brittle strength of cement paste and mortar: A multi-scale engineering mechanics model. Cem. Concr. Res. 2011, 41, 467-476.

30. Pichler, B.; Hellmich, C.; Eberhardsteiner, J.; Wasserbauer, J.; Termkhajornkit, P.; Barbarulo, R.; Chanvillard, G. The counteracting effects of capillary porosity and of unhydrated clinker grains on the macroscopic strength of hydrating cement paste: A multiscale model. In Mechanics and Physics of Creep, Shrinkage, and Durability of Concrete; Ulm, F.J., Jennings, H.M., Pellenq, R., Eds.; American Society of Civil Engineers: Reston, VA, USA, 2013.

31. Königsberger, M.; Hlobil, M.; Delsaute, B.; Staquet, S.; Hellmich, C.; Pichler, B. Hydrate failure in ITZ governs concrete strength: A micro-to-macro validated engineering mechanics model. Cem. Concr. Res. 2018, 103, 77-94.

32. Scheiner, S.; Hellmich, C. Continuum Microviscoelasticity Model for Aging Basic Creep of Early-Age Concrete. J. Eng. Mech. 2009, 135, 307-323.

33. Königsberger, M.; Irfan-ul Hassan, M.; Pichler, B.; Hellmich, C. Downscaling Based Identification of Nonaging Power-Law Creep of Cement Hydrates. J. Eng. Mech. 2016, 142, 4016106.

34. Tamtsia, B.T.; Beaudoin, J.J. Basic creep of hardened cement paste A re-examination of the role of water. Cem. Concr. Res. 2000, 30, 1465-1475.

35. Silva, D.A.; John, V.M.; Ribeiro, J.L.D.; Roman, H.R. Pore size distribution of hydrated cement pastes modified with polymers. Cem. Concr. Res. 2001, 31, 1177-1184.

36. Tian, Y.; Jin, X.Y.; Jin, N.G.; Zhao, R.; Li, Z.J.; Ma, H.Y. Research on the microstructure formation of polyacrylate latex modified mortars. Constr. Build. Mater. 2013, 47, 1381-1394.

37. Plank, J.; Gretz, M. Study on the interaction between anionic and cationic latex particles and Portland cement. Colloids Surf. A 2008, 330, 227-233.

38. Dimmig, A.; Rothenhäusser, B.; Sachsse, S. The influence of redispersibility and of the polymer powders composition on the freeze-thaw resistance of polymer modified mortar. In Proceedings of the 14th Internationale Baustofftagung, Weimar, Germany, 20-23 September 2000; pp. 1095-1103.

39. Neville, A.M. Creep of concrete as a function of its cement paste content. Mag. Concr. Res. 1964, 16, 21-30.

40. Bažant, Z.P.; Prasannan, S. Solidification Theory for concrete creep. I: Formulation. J. Eng. Mech. 1989, 115, 1691-1703.

41. Acker, P. Micromechanical Analysis of Creep and Shrinkage Mechanisms. In Proceedings of the Sixth International Conference Creep, Shrinkage and Durability Mechanics of Concrete and Other Quasi-brittle Materials, Cambridge, MA, USA, 20-22 August 2001; pp. 15-26.

42. Schwarzl, F.R.; Struik, L. Analysis of relaxation measurements. Adv. Mol. Relax. Processes 1968, 1, $201-255$.

43. Constantinides, G.; Ulm, F.J. The effect of two types of C-S-H on the elasticity of cement-based materials: Results from nanoindentation and micromechanical modeling. Cem. Concr. Res. 2004, 34, 67-80.

44. Velez, K.; Maximilien, S.; Damidot, D.; Fantozzi, G.; Sorrentino, F. Determination by nanoindentation of elastic modulus and hardness of pure constituents of Portland cement clinker. Cem. Concr. Res. 2001, 31, 555-561.

45. Zaoutsos, S.P.; Papanicolaou, G.C.; Cardon, A.H. On the non-linear viscoelastic behaviour of polymer-matrix composites. Compos. Sci. Technol. 1998, 58, 883-889. 
46. Kapnistos, M.; Lang, M.; Vlassopoulos, D.; Pyckhout-Hintzen, W.; Richter, D.; Cho, D.; Chang, T.; Rubinstein, M. Unexpected power-law stress relaxation of entangled ring polymers. Nat. Mater. 2008, 7, 997-1002.

47. Chevali, V.S.; Dean, D.R.; Janowski, G.M. Flexural creep behavior of discontinuous thermoplastic composites: Non-linear viscoelastic modeling and time-temperature-stress superposition. Compos. Part A 2009, 40, 870-877.

48. Laws, N.; McLaughlin, R. Self-Consistent Estimates for the Viscoelastic Creep Compliances of Composite Materials. Proc. R. Soc. Lond. A 1978, 359, 251-273.

49. Zaoui, A. Continuum mechanics: A survey. J. Eng. Mech. 2002, 128, 808-816.

50. Hershey, A.V. The elasticity of an isotropic aggregate of anisotropic cubic crystals. J. Appl. Mech. 1954, $21,236$.

51. Powers, T.C.; Brownyard, T.L. Studies of the Physical Properties of Hardened Portland Cement Paste. Res. Lab. Portland Cem. Assoc. Bull. 1948, 43, 101-132.

52. Mori, T.; Tanaka, K. Average stress in matrix and average elastic energy of materials with misfitting inclusions. Acta Metall. 1973, 21, 571-574.

53. Benveniste, Y. A new approach to the application of Mori-Tanaka's theory in composite materials. Mech. Mater. 1987, 6, 147-157.

54. Abate, J.; Valkó, P.P. Multi-precision Laplace transform inversion. Int. J. Numer. Methods Eng. 2004, 60, 979-993.

55. Valkó, P.P.; Abate, J. Comparison of sequence accelerators for the Gaver method of numerical Laplace transform inversion. Comput. Math. Appl. 2004, 48, 629-636.

56. Göbel, L.; Pichler, B.; Osburg, A. Experimental analysis and micromechanics-based prediction of the elastic and creep properties of polymer-modified concrete at early ages. In Proceedings of the 16th International Congress on Polymers in Concrete 2018, Washington, DC, USA, 29 April-1 May 2018.

57. Wang, R.; Wang, P.M.; Li, X.G. Physical and mechanical properties of styrene-butadiene rubber emulsion modified cement mortars. Cem. Concr. Res. 2005, 35, 900-906.

58. Doğan, M.; Bideci, A. Effect of Styrene Butadiene Copolymer (SBR) admixture on high strength concrete. Constr. Build. Mater. 2016, 112, 378-385.

59. Maksimov, R.D.; Sokolov, E.A.; Mochalov, V.P. Effect of temperature and humidity on the creep of polymer materials. Polym. Mech. 1975, 11, 834-839.

60. Scaffaro, R.; Tzankova Dintcheva, R.; La Mantia, F.P. A new equipment to measure the combined effects of humidity, temperature, mechanical stress and UV exposure on the creep behaviour of polymers. Polym. Test. 2008, 27, 49-54.

61. Liu, X.; Wildman, R.D.; Ashcroft, I.A. Experimental investigation and numerical modelling of the effect of the environment on the mechanical properties of polyurethane lacquer films. J. Mater. Sci. 2012, 47, 5222-5231.

62. Lura, P.; Jensen, O.M.; van Breugel, K. Autogenous shrinkage in high-performance cement paste: An evaluation of basic mechanisms. Cem. Concr. Res. 2003, 33, 223-232.

63. Bijen, J.; Su, Z. Polymer cement concrete: A contribution to modling of the microstructure. In Proceedings of the TC 113, Symposium on properties and test methods for concrete-polymer composites, Oostende, Belgium, 6 July 1995; pp. 19-27.

64. Dimmig-Osburg, A. Microstructure of PCC_Effects of polymer components and additives. In Proceedings of the 12th International Congress on Polymers in Concrete, Cairns, Australia, 27-28 September 2009.

65. Kong, X.; Pakusch, J.; Jansen, D.; Emmerling, S.; Neubauer, J.; Goetz-Neuhoeffer, F. Effect of polymer latexes with cleaned serum on the phase development of hydrating cement pastes. Cem. Concr. Res. 2016, 84, 30-40.

66. Wang, R.; Li, X.G.; Wang, P.M. Influence of polymer on cement hydration in SBR-modified cement pastes. Cem. Concr. Res. 2006, 36, 1744-1751.

(C) 2018 by the authors. Licensee MDPI, Basel, Switzerland. This article is an open access article distributed under the terms and conditions of the Creative Commons Attribution (CC BY) license (http:/ / creativecommons.org/licenses/by/4.0/). 